\title{
ESCOLA COMO AGÊNCIA DE CIVILIZAÇÃO: PROJETOS FORMATIVOS E PRÁTICAS PEDAGÓGICAS PARA A EDUCAÇÃO RURAL NO BRASIL (1946-1964)
}

\author{
Flávio Anício Andrade \\ Universidade Federal Rural do Rio de Janeiro, Brasil.
}

\begin{abstract}
Resumo
No presente estudo se propõe uma análise acerca da escola rural no Brasil, no contexto do projeto de expansão dos valores ligados ao espaço urbano e ao concomitante processo de industrialização que se aprofunda na segunda metade do século 20. Para os que pensavam as políticas educacionais do Estado brasileiro, a escola primária rural deveria tornar-se um centro de irradiação dos novos valores do industrialismo, ao incorporar e refletir ela mesma tais valores. 0 contexto histórico em que ocorre tal processo encontra-se marcado pela transformação do Estado em agente promotor de uma nova configuração econômica, política e social no Brasil, sendo o eixo de sua ação o esforço de expansão do setor industrial do país. Concluiu-se que o projeto de expansão e readequação da educação rural teve como objetivo a extensão dos hábitos, atitudes e formas de comportamento característicos de uma civilização industrial.
\end{abstract}

Palavras-chave: escola rural, Estado, industrialismo.

\section{SCHOOL AS AGENCY OF CIVILIZATION: FORMATIVE EDUCATIONAL PROJECTS AND PEDAGOGICAL PRACTICES FOR RURAL EDUCATION IN BRAZIL (1946-1964)}

\begin{abstract}
The present study proposes an analysis about function of the rural school in Brazil in the context of the expansion project of the urban values and the concomitant process of industrialization that deepens in the second half of the 20th century. In the analysis of those who were thinking the educational policy of the Brazilian State, the rural primary school should become a center of irradiation of new values of industrialism to incorporate and reflect herself such values. The historical context in which occurs this process is characterized by the Brazilian State's transformation into a promoter of a new economic, political and social setting in Brazil, being the axis of its expansion effort of the country's industrial sector. This article concludes that the rural primary school expansion and reconfiguration project had like the objective the extension of typical habits, attitudes and behaviors of the industrial civilization.

Key-words: rural school, State, industrialism.
\end{abstract}


Resumen

\section{LA ESCUELA COMO AGENCIA DE LA CIVILIZACIÓN: \\ PROYECTOS FORMATIVOS Y PRÁCTICAS PEDAGÓGICAS \\ PARA LA EDUCACIÓN RURAL EN BRASIL (1946-1964)}

Este estudio tiene por objeto un análisis a cerca de la escuela rural en el Brasil en el contexto del proyecto de expansión de los valores asociados al espacio urbano mientras en que el proceso de industrialización que se profundiza en la segunda mitad del siglo 20 . El contexto histórico en que sucede este proceso está marcado por el cambio del Estado en agente promotor de un nuevo desarrollo económico, político y social en Brasil, siendo el eje de su acción el esfuerzo de expansión del sector industrial del país. Se concluyó que el proyecto de ampliación y reorganización de la educación rural tuvo como objeto la extensión de los hábitos, actitudes y maneras de comportarse característicos de una civilización industrial.

Palabras-clave: escuela rural, Estado, industrialismo.

\section{ÉCOLE COMME AGENCE DES CIVILISATIONS: \\ PROJETS DE FORMATION ET PRATIQUES PEDAGOGIQUES POUR L'EDUCATION RURALE AU BRESIL (1946-1964)}

Résumé

Cette étude propose une révision de l'école rurale au Brésil dans le cadre du projet d'extension des valeurs liées à l'espace urbain et a le processus concomitant d'industrialisation qui se approfondissement dans la seconde moitié du 20e siècle. Pour ceux qui pensaient la politique éducative du gouvernement brésilien, l'école primaire en milieu rural devrait devenir un centre de diffusion de nouvelles valeurs de l'industrialisme après intégrer et refléter ces valeurs elle même. Le contexte historique dans lequel ce processus se produit est marqué par la transformation de l'État en agent favorisant de la fixation d'un nouveau développement économique, politique et sociale au Brésil, étant l'axe de son mouvement le effort d'élargir le secteur industriel du pays. II a été conclu que le projet d'expansion et de réaménagement de l'éducation en milieu rural vise à l'extension des habitudes, des attitudes et des comportements caractéristiques d'une civilisation industrielle.

Mots-clé: école rurale, l'État, industrialisme. 
$\mathrm{N}$ o presente estudo se propõe uma análise acerca do papel de agência de civilização atribuído à escola rural no Brasil, frente ao projeto de expansão dos valores ligados ao espaço urbano e ao concomitante processo de industrialização, que se aprofundou na segunda metade do século 20.

Tendo por base uma análise das pesquisas, projetos e propostas referentes ao tema do ensino primário rural, publicados entre o fim da ditadura varguista e o advento do golpe civil-militar de 1964 nas páginas da Revista Brasileira de Estudos Pedagógicos, órgão oficial de divulgação e formação do Instituto Nacional de Estudos Pedagógicos - Inep -, investigou-se, mais particularmente, o papel estratégico atribuído à escola rural como espaço privilegiado do esforço de conformação da população do campo brasileiro frente aos valores, hábitos e práticas característicos, tanto do trabalho em moldes industriais, quanto do estilo de vida urbano que lhe é consentâneo.

A preocupação com a educação da população rural se constitui em tema da ação do Estado no Brasil a partir dos anos 1930. As razões de tal emergência encontram-se ligadas à necessidade de disseminação da educação das populações, o que poderíamos denominar uma civilização do trabalho no Brasil. No entanto, foi especialmente a partir da segunda metade da década de 1940 que a extensão da educação da população rural se apresentou, tanto como forma de disseminação dos valores e comportamentos emanados do meio urbano, quanto como mecanismo de fixação dos homens e mulheres do campo em seu lugar de origem.

Parte-se do entendimento de que o esforço de fixação do homem do campo, na sua comunidade de origem, passava, no momento histórico em pauta, pela elevação das capacidades de trabalho e organização daquele sujeito, movimento que se configurava, em última instância, como de extensão de um determinado projeto de cidadania. As práticas pedagógicas da escola primária rural aparecerão, na formulação dos que pensavam as políticas educacionais do Estado brasileiro, como promotora de uma aprendizagem daqueles mencionados valores, tanto por parte dos alunos imediatamente sob seus cuidados, quanto por parte dos pais e da comunidade do entorno da escola de maneira geral. A escola primária rural deveria tornar-se um centro de irradiação dos novos valores do industrialismo, ao incorporar e refletir ela mesma tais valores.

O período de governo democrático que sucedeu a queda do Estado Novo e que tinha como líder do executivo o ex-chefe do Estado-Maior do Exército neste mesmo último período, general Eurico Gaspar Dutra, pode ser considerado como um momento marcado pelo esforço, em bases mais concretas, de alargamento da oferta de educação formal para um contingente maior da população brasileira e de tentativa de superação dos índices de analfabetismo desta mesma população.

A partir da segunda metade da década de 1940, com o fim da primeira parte mais extensa da era Vargas e, consequentemente, com o processo de redemocratização da sociedade brasileira, aparece fortemente, tanto a necessidade da incorporação de um maior contingente populacional aos mecanismos políticos clássicos da democracia liberal, entre os quais o direito essencial de escolher seus representantes no parlamento, quanto a necessidade de, pela educação, disseminar a nova concepção de vivência social calcada nos valores do individualismo, da liberdade, no sentido dado pelo ideário liberal, isto é, como garantia formal dos direitos de igualdade, de ascensão social e da solidariedade social. 
Ao lado dessa função política, o processo de extensão da escolarização se afirmou como uma necessidade, tendo em vista o objetivo da melhoria qualitativa da força de trabalho nacional, bem como, consequência deste primeiro fator, a maior racionalização dos processos produtivos, tanto industriais, quanto agrícolas. A consecução de tal objetivo, por seu turno, contribuiria, ao permitir a elevação da riqueza do país e supostamente, sua maior divisão, para a consolidação da nova ordem social democrática.

Neste contexto, a melhoria quantitativa e qualitativa da precária educação rural existente impunha-se porque, como o usufruto dos direitos políticos básicos encontravase interditado aos que não eram alfabetizados, tornava-se necessário, do ponto de vista dos princípios formais que embasavam a concepção de mundo liberal então anunciada, a qual se procurava generalizar nesse momento tendo em vista a recomposição em novas bases - no quadro de uma sociedade onde a disputa entre os atores políticos individuais e coletivos tornava-se um fenômeno natural - das relações dominantes de poder, oferecer a posse da cultura letrada a um maior contingente de brasileiros.

Por outro lado, com a necessidade do aumento da qualificação da força de trabalho nacional, tendo em vista responder à expansão do processo de desenvolvimento econômico, a melhoria da estrutura educacional formal aparecia como pré-condição importante para a garantia da existência daquela base humana física e mentalmente, conforme os novos processos de produção industrial.

Segundo o censo realizado em 1940, mais da metade da população brasileira adulta não possuía instrução. $O$ investimento no ensino primário fazia-se necessário, tanto para a constituição de uma base humana mais ampla da qual se originariam os futuros componentes da força de trabalho adequada ao processo de expansão das formas de produção racionais no âmbito dos setores industrial e agrícola, quanto com vistas à formação de sujeitos melhor preparados para participar das novas regras de convivência democrática instituidoras de uma ordem social pautada nos princípios ideológicos do receituário liberal.

Se, por um lado, a preocupação com o momento inicial da formação educacional da população do país assumia discursivamente um espaço bastante significativo no projeto governamental exposto por Dutra, por outro, o aprofundamento do processo de complexificação da base produtiva nacional estava a exigir a formação de quadros profissionais possuidores de um maior conhecimento escolar formal. Dessa forma, também era necessário um investimento do Estado no sentido da preparação mais ampla daqueles quadros.

Trata-se assim, como já indicado acima, de potencializar a contribuição da educação para o desenvolvimento econômico, o qual, por sua vez, constituir-se-ia na condição necessária para o estabelecimento e manutenção, sem agitações, da ordem social. A política educacional do futuro governo foi orientada, portanto, pelo objetivo de formação ampliada de uma força de trabalho pronta para se inserir em um processo produtivo organizado segundo os princípios científicos de realização do trabalho.

É no quadro deste projeto de reconfiguração da sociedade brasileira que a educação rural assumiu a função de civilização para uma nova ordem social acima apontada. 


\section{A escola rural como agência de civilização do campo}

A tarefa civilizatória a ser cumprida pela educação primária não deveria incidir tão somente sobre os filhos da população urbana. Fazia-se necessária também, até como meio de minorar o problema da intensidade do fluxo migratório para as áreas urbanas então em franca expansão, uma ação dirigida de interiorização da ordem social em construção, tanto em seus aspectos econômicos, quanto políticos.

No contexto deste projeto, a escola primária rural tornou-se o meio por excelência de levar à maior parte da população do país os novos valores, hábitos de ação e pensamento e os conhecimentos técnicos tidos como promotores da elevação dos padrões de produção e, portanto, de condições de vida desta mesma população.

O cumprimento deste papel civilizador e integrador da escola encontrar-se-á intimamente ligado ao projeto de formação de um novo tipo de profissional docente. Mais do que professoras urbanas transplantadas para as zonas agrárias, procedimento padrão até então e também patente fracasso em termos da permanência destas nas escolas por um tempo razoável, tratava-se de criar uma professora rural, isto é, natural das localidades a serem influenciadas pela presença da escola ou, na pior das hipóteses, de regiões rurais de seus respectivos Estados.

Mais do que isso, professora rural e escola rural deviam formar uma mesma unidade. A presença material e simbólica dos dois elementos deve produzir já de per si um efeito educador. Dessa forma, se todo prédio escolar de novo tipo - aquele que também neste momento vai ser planejado como em si mesmo um fator de irradiação do espírito desse novo tempo que se anuncia - trará contígua a residência da professora, esta deve fazer com que seus hábitos domésticos e pessoais - conservação, arrumação e decoração de seu lar, maneira de se vestir, falar e agir em público - transmitam eles também um novo padrão de existência e comportamento civilizado para os que se encontram, por assim dizer, à sombra da escola.

Para cumprir sua missão educativa, nos termos acima expostos, todos os aspectos afeitos à vida da instituição escolar deveriam ser entendidos como elementos importantes de transmissão de uma cultura e de um padrão de comportamento a serem idealmente seguidos, tendo em vista o intuito da formação de um novo modelo de cidadão e de trabalhador.

Caberia aos mestres cuidar para que a presença da escola funcionasse como uma espécie de farol que irradiasse a luz de uma nova forma de sociabilidade, governada pela ordem e pela razão e assentada na valorização do homem que trabalha. Tratava-se de moldar o interior do país a partir dos novos valores gestados nas cidades do trabalho e do progresso, isto é, do modelo de vida familiar liberal, da proposta de participação trazida pelo novo regime político e dos princípios de organização em moldes racionais da vida produtiva. Melhorar a formação das crianças das áreas interioranas do país aparecia como uma garantia futura de evitar a permanência de bolsões de resistência à ordem do trabalho.

Sendo assim, tal papel de civilização a ser cumprido pela escola assumia importância nas áreas rurais na medida em que a população rural, ao encontrar-se excluída dos benefícios facultados aos trabalhadores urbanos, possuía muito menos motivos para entusiasmar-se com as promessas da chegada de um novo mundo em que a miséria e a injustiça não mais encontrariam lugar. 
O interesse em relação à população rural tinha também razões bastante pragmáticas a partir do momento em que, frente à significativa migração ocorrida no decorrer dos anos 1930 em diante, particularmente do Estado de Minas Gerais para o Distrito Federal e para a cidade de São Paulo, os grandes centros industriais do país, a adaptação desses novos contingentes populacionais à vivência nos ambientes urbano e fabril tornava-se uma necessidade premente.

Dessa forma, se as futuras levas vindas do interior já se encontrassem compartilhando as regras de civilidade e a mentalidade do trabalho, isto é, os hábitos e valores correspondentes à ordem social em construção, sua transformação em uma força de trabalho adequada aos ditames da produção, orientada segundo as diretrizes do movimento de racionalização, se apresentaria como uma tarefa mais fácil. Como afirmou M. B. Lourenço Filho, então encarregado da direção do Departamento Nacional de Educação, a escola rural deveria cumprir uma função preventiva no quadro das necessidades do processo de desenvolvimento do país:

A influência geral das condições econômicas não se alterarão também, sem grande esforço no sentido dessa educação. A produção, além dos fatores técnicos, restritamente considerados, repousa no ânimo de produzir, no entusiasmo pelo trabalho, e no sentido de produzir além das necessidades de consumo elementar. Algumas observações feitas em fábricas de São Paulo e do Rio têm demonstrado que, após a elevação de salários, numerosos trabalhadores deixaram de ser assíduos às fábricas, na exata proporção do aumento concedido. Na mais alta percentagem, ficou verificado também que esses operários eram analfabetos. "Trabalhar, eu não!" é a triste filosofia dessa pobre gente "marginal" às solicitações da cultura de nosso tempo. (Lourenço Filho, 1947, p. 14)

Disseminar uma determinada racionalidade conforme a necessidade de aumento da produtividade da força de trabalho, a qual implica na interiorização por parte do alfabetizando de um ideário orientador de sua vivência cotidiana, elaborado e compartilhado pelos que possuem os meios de produção. Dessa forma, fica claro que tão ou mais importante que a obtenção dos rudimentos da leitura e da escrita era a aprendizagem de uma dada maneira de ser, de novos hábitos e atitudes conformadoras do novo sujeito produtivo adequado às novas formas assumidas pelo desenvolvimento capitalista no Brasil.

Em 1947 o presidente da República encarrega o Instituto Nacional de Estudos Pedagógicos de colocar em prática um amplo programa de construção de escolas rurais e de simultânea formação dos quadros docentes a elas destinados. Na mensagem presidencial encaminhada ao Congresso Nacional naquele ano, era exposta a direção que o programa deveria assumir:

Ao órgão federal orientador dos problemas pedagógicos foi confiada a missão de selecionar os tipos mais apropriados e econômicos de prédios escolares, para as zonas rurais, e de distribuir, equitativamente, os novos recursos disponíveis entre as unidades da Federação, mediante acordos bilaterais. Com essa primeira etapa do trabalho planejado, já estão previstas perto de 1.200 novas escolas rurais, das quais pouco mais da metade em construção, estando algumas em vias de acabamento. [...] o plano do Governo Federal é de ampliar a sua ação para a construção de 
mais 2000 escolas e estender sua ação supletiva também à criação de 40 escolas normais para a formação de professores rurais, integrados nas condições de vida e nos problemas específicos e imediatos das zonas em que se processará sua atividade docente. A falta de um professorado primário, recrutado entre as próprias populações rurais e preparado especialmente para enfrentar os problemas do meio, era, até hoje, uma das mais graves lacunas do nosso sistema escolar primário e uma das principais causas do analfabetismo que grassa em nosso meio rural. (Dutra, 1950, p. 75)

Vê-se, assim, que a tarefa civilizatória a ser cumprida pela educação primária não deveria incidir tão somente sobre os filhos da população urbana. Fazia-se necessária, também, até como meio de minorar o problema da intensidade do fluxo migratório para as áreas urbanas então em franca expansão, uma ação dirigida de interiorização da ordem social em construção, tanto em seus aspectos econômicos, quanto políticos.

A construção simbólica dessa ordem social virá teve vinculação com a construção material dos prédios escolares. E não apenas de escolas isoladas nas localidades mais interioranas, senão também as que, contanto com maior número de salas e complexidade de instalações, seriam erguidas nas sedes dos municípios rurais. Na mensagem presidencial de seu último ano de mandato, o general Eurico Dutra se manifestou exemplarmente quanto ao tema:

Embora adstrito a caracteres de padronização, o tipo de construção [da escola rural] obedece às condições de clima, e oferece a singularidade de possuir residência contígua para o professor, dotada de recursos modernos, em contato com os quais o aluno rural se familiariza com uma casa confortável, diferente de sua choupana. Vale ainda ressaltar que o regime de distribuição dessas escolas abrange não apenas a população rural brasileira, senão também os habitantes das zonas de fronteiras e colonização. [...] Não se limita, porém, a escolas rurais o plano governamental; estende-se também a ponto de abranger a construção de grupos escolares, muitos dos quais já se acham em fase de conclusão. Em 1948 e 1949, foram distribuídos, entre os Estados e Territórios, 220 grupos escolares, dotados de 4 ou 5 salas de aula, área coberta para recreio, secretaria, pequena biblioteca, gabinete dentário, e até residência para o diretor. Com tal iniciativa visou o Governo atender à população das pequenas cidades, verdadeiras comunidades rurais do nosso hinterland, onde as escolas de mais de uma classe geralmente não dispõem de boas instalações. (Dutra, 1950, p. 102)

Para cumprir sua missão educativa, nos termos acima expostos, todos os aspectos afeitos à vida da instituição escolar deveriam ser entendidos como elementos importantes de transmissão de uma cultura e de um padrão de comportamento a serem idealmente seguidos, tendo em vista o intuito da formação de um novo modelo de cidadão e de trabalhador.

$\mathrm{Na}$ verdade, tratava-se de moldar o interior do país a partir dos novos valores gestados nas cidades do trabalho e do progresso, isto é, do modelo de vida familiar liberal, dos valores constituintes da ordem social que se intentava consolidar e dos princípios de organização em moldes racionais da vida produtiva. 
Não por coincidência, no contexto do processo de estabelecimento de uma cooperação mais constante com os Estados Unidos da América, que se seguiu ao fim da Segunda Guerra Mundial, marcado pela criação da política da aliança para o progresso, foi este país que veio a servir de principal modelo de referência para a implantação do programa de expansão da educação rural no Brasil. Além da continuidade das ações desenvolvidas durante a vigência do acordo que instituiu a Comissão BrasileiroAmericana de Educação das Populações Rurais, cujas atividades permaneceram a cargo do Ministério da Agricultura quando de seu término em 1950, foram estreitados os laços de cooperação entre o Ministério da Educação, pela atuação executiva do Instituto Nacional de Estudos e Pesquisas Educacionais, e representantes de instituições governamentais ou universitárias estadunidenses, os quais eram, eventualmente, contratados como consultores e mesmo dirigentes junto a programas governamentais brasileiros.

Um dos exemplos desta relação de proximidade foi o convite feito ao professor Robert King Hall, da Universidade de Columbia, para acompanhar e aconselhar o referido programa de expansão do ensino escolar rural e que assumiu a direção do centro de formação de professores rurais criado pelo Inep. Em avaliação feita em 1950, já ocupando a função de diretor do Seminário de Educação Rural sediado no Rio de Janeiro, afirmava, em relação ao plano de expansão do ensino primário rural, no que se refere àquele efeito pedagógico sobre a população rural presente na materialização mesma da edificação escolar, que tal plano de construção de escolas rurais

ajuda a educar a comunidade em que está sediada a escola. Neste ponto o plano também se vale de três meios, para colimar este objetivo. O primeiro é a própria existência física da residência do professor. Representa o modelo de um tipo de casa e de vida superior a tudo quanto existe na localidade; e, no entanto, é uma coisa real e atingível. Não se cometeu o grave erro psicológico de afrontar a comunidade local com uma casa luxuosa ou grandiosa, completamente fora do alcance dos membros da comunidade. O segundo é o jardim, horta ou criação de animais (galinhas ou mesmo gado). Boas sementes, métodos modernos e um certo orgulho, acompanhado de cuidado, resultaram em jardins excelentes,já imitados por alguns pais de alunos. O terceiro é um método sutil, a própria arquitetura das escolas. Logo que foram projetadas, surgiram severas críticas; não eram imponentes, sua simplicidade e ausência de ornamentos fazia lembrar as residências de escravos do século passado. A experiência, todavia, veio demonstrar que tais críticas não são necessariamente fundadas. Localizando-se a escola numa posição de destaque, frequentemente no topo de um pequeno morro ou colina, que domine a vila e seus arredores, a estrutura, embora simples, pode revestir-se de uma certa imponência e dignidade. A arquitetura é extremamente funcional e a conservação deve ser de 30 a $35 \%$ inferior à dos prédios inicialmente construídos nas cidades do Estado que visitei. A prova da aceitação desse tipo de construção pela população local é que muitos prédios particulares recentemente construídos não passam de cópias modificadas da escola do Inep. (Hall, 1950a, p. 115)

Este autor elabora uma proposta de programa mínimo, equipamento e métodos para uma escola rural elementar a ser implantado nas novas escolas rurais já construídas e em construção, mais precisamente: 2.250 escolas primárias rurais e 55 grupos escolares 
construídos e 2.110 escolas, 65 grupos escolares e 25 escolas normais rurais em construção, além de, também segundo o próprio King Hall, 1.800 escolas primárias rurais, 100 grupos escolares, 12 escolas secundárias e 20 escolas normais rurais com recursos para sua construção já autorizados (Hall, 1950a). Tal proposta orientou-se pela preocupação de tornar cada momento ou aspecto da vida da escola rural em uma oportunidade para a transmissão e interiorização das novas qualidades a serem desejavelmente possuídas pelo novo homem do campo. Sua diretriz básica compunha-se de 12 itens orientadores:

1) O objetivo político deve ser a formação de bons cidadãos para a nação democrática do Brasil. 2) O objetivo social deve ser formar um membro pensante, competente, que saiba se dirigir - da organização econômica e sociológica do Brasil. 3) O objetivo social deve ser dar a cada indivíduo oportunidades de se desenvolver ao máximo, nas áreas de seu maior interesse e capacidade, desde que dignas. 4) O programa deve ser flexível, democrático, funcional, baseado nas necessidades comprovadas, do indivíduo e da comunidade. 5) O programa de cada escola deve ser determinado pelos professores locais, em colaboração com o público em geral e com as autoridades estaduais de educação, e deve satisfazer a certos requisitos gerais mínimos. 6) O programa deve consistir de experiências educativas em largas áreas culturais e habilidades práticas, não devendo constar simplesmente de uma série de aulas em matérias formais. 7) Os prédios, pátios e equipamento devem ser funcionais, econômicos, fáceis de limpar e consertar, com materiais e mão-de-obra locais. 8) Os prédios, pátios e equipamento devem adaptar-se aos programas de atividades, aulas práticas de trabalhos manuais, a um curriculum tipo projeto, e devem facilitar os trabalhos de experiência, especialmente em agricultura e artes e ofícios. 9) Os prédios, pátios e equipamentos devem integrar-se na comunidade local: servindo de modelo para a construção local e a higiene pública, métodos agrícolas e indústrias domésticas; devem dar ao professor uma residência condigna, à altura da profissão; devem demonstrar as vantagens práticas e culturais da educação; evitar choques e conflitos com a comunidade, quer pela ostentação, quer pela negligência. 10) Os métodos empregados devem ser absolutamente compatíveis com os objetivos democráticos e culturais do curriculum. 11) Os métodos empregados devem ser destinados a aproveitar e desenvolver - e não a selecionar e refugar - todos aqueles que não atingem os padrões arbitrariamente estabelecidos nas matérias tradicionais. 12) Os métodos empregados devem ser determinados pela personalidade de cada professor, e a ela adaptados, mas devem ressaltar a experiência prática, "aprender a fazer, fazendo", trabalho físico, um programa ativo, e grandes unidades de estudo de tipo "projeto". (Hall, 1950b, p. 31)

Podemos ver que uma qualidade fundamental desejada da futura escola rural é a de ser capaz de influenciar os habitantes da comunidade à sua volta. Influência essencial, tendo em vista o cumprimento de sua função pedagógica reformadora. Estava em jogo, portanto, muito mais do que simplesmente a oferta de ensino em escolas localizadas na zona rural.

Num primeiro momento deveriam ser interiorizadas pelos alunos, simultaneamente à aprendizagem dos conteúdos formais, também características pessoais que, pelo contato cotidiano, possam vir a ser transmitidas exemplarmente aos seus pais e familiares. Nas 
palavras do então secretário de Educação do Estado de Minas Gerais e futuro ministro da Educação,

com o correr do tempo verificareis que o vosso pequenino mundo irá sendo transformado pela vossa escolazinha, antes mesmo que outros agentes e outros meios intervenham no processo de sua civilização. E a primeira transformação será provavelmente a mudança de atitude da vossa comunidade social para com a vossa comunidade escolar - sua miniatura, sua modeladora, sua criatura e sua criadora. A comunidade não é diferente da dos vossos alunos, que são, via de regra, um espelho que repete facilmente as atitudes e os atos da escola, isto é, da professora. Mais da metade do processo educacional é um jogo de espelhos e reflexos. (Renault, 1955, p. 242)

A escola rural devia assumir ela mesma a função de espaço físico e social no qual se materializariam valores, hábitos e formas de comportamento exemplares para a comunidade. Por meio dela deveria ser colocado em marcha, tanto um processo de elevação cultural, quanto, e este talvez o de maior importância neste caso, de melhoria econômica daquela mesma comunidade. Neste último caso ela atuaria, contando com a ajuda dos alunos já anteriormente mobilizados ao longo do processo escolar, incentivando a adoção de novas formas de organização produtiva por parte da comunidade local. $\mathrm{Na}$ forma de um chamamento à ação, o futuro ministro Abgar Renault perguntava e propunha aos novos mestres da educação primária rural:

Quem sabe se podereis também organizar um clube agrícola, ligado a ele, uma cooperativa rural capaz, com o correr do tempo, de transformar-se num instrumento, não apenas da escola mas também da comunidade? Talvez estejamos a sonhar demais... Mas não estamos: é preciso não esquecermos que o destino da escola é precisamente esse transbordamento, essa capacidade de ultrapassar-se a si mesma, de transcender-se e ir além dos seus pobres limites físicos... [...] conseguireis levá-la por diante, se, conhecidos os seus princípios gerais e o seu funcionamento, puderdes contar com a boa vontade de um grupo de pessoas da região, a quem mostreis as vantagens que dela advirão para todos. Que tal se organizásseis os vossos alunos em comissões e cada uma delas tivesse como patrono (patrono, e não chefe) uma pessoa da localidade suficientemente esclarecida acerca da natureza e das finalidades de uma cooperativa? (Renault, 1955, p. 240)

A escola deveria, portanto, se transformar em um espaço de encontro dos membros da comunidade local, no qual estes se veriam levados a formular e discutir seus problemas cotidianos, tendo em vista a sua mobilização, com vistas à resolução daqueles problemas e de acordo com suas possibilidades.

Como condição inicial de cumprimento desta responsabilidade, a professora rural devia agir no sentido de convencer os moradores próximos acerca da importância da instituição escolar como instrumento de melhoria de suas condições sociais e, principalmente, da de seus filhos. Como afirma Roberto Moreira, um dos mais atuantes funcionários do Inep no âmbito da discussão da educação brasileira na segunda metade dos anos 1950, 
criar a verdadeira escola rural, com todas as funções que lhe devem ser atribuídas, é também, em grande parte, mudar a atitude das populações rurais para com as instituições escolares, pois qualquer mudança de atitude requer trabalho de persuasão, que pode ser mais ou menos longo. O principal agente dessa persuasão tem que ser o professor. Daí a importância da sua formação, o que significa que a escola rural, em vez de qualquer um que saiba ler, escrever e contar, exige um especialista que deverá ter tido formação adequada. [...] As técnicas de relações públicas, de comunicação com o homem simples e semi-analfabeto, quando não analfabeto, do interior, os meios de organização e associação que podem ser postos em execução, tendo em vista os diversos padrões culturais do nosso rurícola, o conhecimento de seus interesses dominantes e de seus problemas mais angustiantes, são outras tantas coisas de que o professorando precisa adquirir consciência muito clara e precisa. (Moreira, 1957, p. 120)

Trata-se, também, para este autor, de propiciar a formação de sujeitos, alunos e seus pais, em condições de produzir melhorias na realização dos processos de trabalho e produção habituais da localidade. Menos que uma formação puramente instrumental, estaria em jogo a incorporação de uma racionalidade, materializada no hábito da observação e da avaliação intelectual do que se viu, característica das sociedades desenvolvidas no sentido do uso crescente dos conhecimentos e métodos científicos na esfera da produção industrial:

O objetivo primordial da escola primária rural não é formar o agricultor, mas sim preparar a criança para a vida rural, fazendo-a participar consciente e orientadamente dessa vida. Neste caso, em vez de confiná-la em certas práticas agrícolas, nos limites do terreno escolar, práticas essas que podem divergir fundamentalmente das em uso na área comunitária, o melhor é levar os alunos a observar e apreciar o próprio trabalho rural dos adultos, inclusive fazendo-os pensar sobre esse trabalho em termos de economia, de produção, de equilíbrio e condicionamento das forças naturais e de proteção e aproveitamento dos recursos naturais. Este mesmo trabalho, se a escola conseguir ser um centro de comunidade, é o que compete ao professor desenvolver junto aos adultos e às famílias, por meio de reuniões, de debates, de conversas, das leituras que a biblioteca da escola proporcionar, etc. (Moreira, 1957, p. 123)

Tratava-se, portanto, de promover a integração dos sujeitos produtivos vindouros já desde as primeiras etapas institucionais de sua socialização. Dessa forma, ao cumprir tal função, a escola, pela ação profissional dos docentes, tornar-se-ia um dos pilares de sustentação da nova ordem social em construção. Isto porque o espaço formativo escolar deveria se constituir em um lugar privilegiado de disseminação daqueles valores, atitudes e comportamentos a serem desejavelmente incorporados pelo novo homem brasileiro, isto é, os trabalhadores e cidadãos conformes às novas formas de sociabilidade que se intentava generalizar na fábrica e na sociedade.

Longe de representar, pura e simplesmente, a opinião pessoal de alguns poucos dirigentes no seio do aparelho de Estado, tal concepção do sentido de formação de sujeitos industriosos e capazes de resistir ao apelo de ideologias antagônicas à visão de mundo liberal a ser imprescindivelmente assumido pela escola rural, encontrava forte 
repercussão no interior do aparelho de Estado. Com efeito, menos de um ano depois da publicação das considerações do professor Hall acima expostas, o Departamento Nacional de Educação do Ministério da Educação e Saúde, em março de 1951, iniciou o planejamento da Campanha Nacional de Educação Rural - CNER -, a qual viria a ser executada a partir do ano seguinte até o ano de 1963. Na sua criação considerou-se que

contrariando as tradições paternalistas que reinam em grande parte das nossas comunidades rurais, torna-se necessário estimular a participação ativa do povo na grande tarefa da auto-educação. O senso comunitário tinha de ser despertado num povo de individualistas. E, ao mesmo tempo, o educador teria de escolher técnicas educativas que dessem aos homens do meio rural a noção da própria valia, juntamente com o sentimento de independência e o senso de responsabilidade, sem o que não se constroem povos, mas somente massas submissas. (Nóbrega, 1954, p. 184)

Tendo como inspiração o projeto especial para a criação de uma rede mundial de centros regionais de educação fundamental, elaborado sob os auspícios Unesco, a CNER, além da promoção de estudos acerca dos vários aspectos da vida rural brasileira, da formação de quadros responsáveis pelas atividades de educação rural e da oferta de apoio financeiro a instituições públicas e privadas que realizassem atividades de mesma natureza e objetivos, tinha os seguintes objetivos:

Promover e estimular a cooperação das instituições e dos serviços educativos existentes no meio rural e que visam ao bem comum; concorrer para a elevação dos níveis econômicos da população rural pela introdução, entre os rurícolas, de técnicas avançadas de organização e trabalho; contribuir para o aperfeiçoamento dos padrões educativos, sanitários, assistenciais, cívicos e morais das populações do campo. (Nóbrega, 1954, 184)

O papel do professor rural como irradiador desses novos valores, hábitos e atitudes tem a sua condição de realização ligada à própria centralidade a ser adquirida pela escola. Esta se apresentaria, como já indicado, em uma espécie de farol, a partir do qual a comunidade em seu entorno seria, paulatinamente, guiada, influenciada e organizada no sentido da aquisição de novas práticas de trabalho e organização da vida individual e coletiva. Como afirmou o coordenador da CNER, por ocasião de seu sétimo aniversário, ou seja, já durante o período governamental em que Juscelino Kubitschek esteve á frente do executivo federal,

dois terços dos 56.000 .000 da população do Brasil vivem em tristes, primitivas e penosas condições, presas [...] da ausência de processos racionais de trabalho e de produção, da falta de estímulo, enfim, e de meios que os condicionem à auto-superação de seus males humanos e mesológicos. São problemas com base, portanto, na "cultura" em que se acham mergulhadas as populações rurais. [...] De nada adianta [...] instalar escolas nas zonas rurais, sem a correspondente preparação e compreensão do professor para a tarefa lenta e segura que deverá desempenhar de educador e de desbastador, estendendo a escola para o lar rural, para o sítio, para a "colônia", para a vila e, principalmente, para o 
futuro, vivificando o alfabeto para o meio e o próprio meio para a expansão daquele. (CNER, 1959, p. 11)

Melhorar a qualidade da formação escolar da população brasileira tornava-se, assim, um dos principais requisitos para a existência de uma força de trabalho capaz de produzir de acordo com as demandas postas pelos novos processos de organização e produção industriais. Segundo o presidente da República,

a própria diretriz imprimida aos novos programas da educação, no Brasil, visa, em última análise, a elevar os nossos níveis de produtividade, pela adaptação dos currículos escolares às necessidades do desenvolvimento.

Com um sólido preparo técnico em nível primário e médio, o trabalhador brasileiro verá crescer os índices de rendimento de sua atividade e conquistará um padrão de vida mais alto, sem que, no mesmo passo, se agrave o custo da produção. (Kubitschek de Oliveira, 1956, p. 224)

Trata-se, neste momento, no que diz respeito à educação formal básica, de melhorar a qualidade da formação escolar da população, pelo menos daquela parte que fazia usufruto efetivo do direito à educação constitucionalmente assegurado, pelo aumento do tempo de permanência na escola, dando, simultaneamente, um caráter de primeira instância de preparação para o trabalho à etapa inicial do processo de escolarização.

Tal medida se justificaria não apenas tendo em vista a elevação do padrão de qualidade da formação escolar, mas como forma de prevenção do que Juscelino Kubistchek denominou hiato nocivo, isto é, o espaço de tempo entre a conclusão do curso primário e o ingresso no mercado de trabalho o qual, por força de lei, não poderia dar-se antes de o candidato a um posto de trabalho haver completado quatorze anos de idade. Para o então presidente da República, este período, em torno de dois anos, tornava-se um convite permanente à vadiagem e, muitas vezes, à pura e simples delinqüência, para aqueles que não ingressassem no curso secundário.

A solução para tais problemas se constituiria, portanto, na inclusão de duas séries complementares ao curso primário normal, durante as quais o aluno tomaria contato sistematizado com o mundo do trabalho pela aprendizagem de determinadas atividades produtivas básicas. Apontava-se o distanciamento entre a escola primária e as novas necessidades trazidas pelo desenvolvimento econômico-social do país como o grande problema a ser resolvido no que se refere à organização daquele nível de ensino em particular e, mesmo, da educação nacional de modo geral:

No Brasil, [...], a evolução das necessidades sociais não foi acompanhada da evolução do sistema escolar. A educação primária é considerada uma ampliação da capacidade normal das pessoas verem e sentirem as coisas. Limita-se, praticamente, aos rudimentos da escrita, da leitura e do cálculo. Urge, portanto, que o ensino primário eduque também para o trabalho, transmitindo o que o indivíduo precisa aprender, para cobrir as necessidades do trabalho em sua variada forma, atendendo, assim, à real integração na economia e na sociedade modernas. Tais objetivos podem ser alcançados num segundo nível de ensino elementar, acrescentando-se às 4 séries já existentes, mais duas. Essa escola elementar de segundo grau, ou cursos complementares, se constituiria pelo processo completo de formação básica, capaz de permitir às novas gerações o ingresso na vida profissional da sociedade. (Kubitschek de Oliveira, 1956, p. 212) 
O currículo a ser cumprido pelos alunos sem fortuna neste período complementar de formação, nesta escola de formação para o trabalho, compunha-se de quatro horas diárias de estudo das disciplinas formais, seguidas de duas horas de aulas ministradas nas oficinas que seriam construídas em anexo às escolas. Nestas últimas ocorreria uma iniciação em "operações mecânicas e artesanais, com o caráter de primeira preparação para a vida prática" (Kubitschek de Oliveira, 1957, p. 159).

Após o breve e conturbado mandato presidencial de Jânio Quadros, 31 de janeiro a 25 de agosto de 1961, assumiu o governo um herdeiro do legado varguista de suposto comprometimento com as chamadas classes trabalhadoras: João Goulart.

Sob o binômio democratização da cultura e habilitação profissional, a política educacional do último governo civil antes do período dos governos militares, voltou a ter como objetivo, frente às novas condições de complexificação da sociedade brasileira, ao lado da inseparável formação para o trabalho produtivo, a integração nos espaços de participação política locais e a extensão da prerrogativa de influir pelo voto na vida institucional do país daquela significativa parte da população que se encontrava ainda sem a posse da capacidade de leitura e escrita básicas:

Pretende ainda o governo, no ano de 1964, promover ampla mobilização para alfabetizar mais de 5 milhões de brasileiros que vivem marginalizados por não possuírem o mínimo de condições culturais para participar do sistema de produção e do processo político que, cada vez mais, exigem cidadãos capazes de velar pelos interesses da comunidade. Nessa mobilização dever-se-á desenvolver ação cuidadosamente planejada, para que sejam utilizadas técnicas modernas e meios suficientes, aptos não apenas a levar o analfabeto ao domínio do mecanismo da leitura e da escrita, mas também a habilitá-lo a participar conscientemente da vida política. (Goulart, 1964, p. 367)

No entanto, mesmo com a novidade da previsão do uso de espaços não-escolares para a realização de atividades de alfabetização organizadas segundo o sistema Paulo Freire, permaneceu como uma constante a defesa do caráter de civilização para o mundo do trabalho de toda e qualquer modalidade de formação inicial, em particular aquela ministrada nas áreas rurais. O próprio Paulo Freire, em que pese uma orientação menos explicitamente instrumental de sua concepção acerca da escola primária, não se encontra tão distanciado daquela concepção:

De uma revisão orgânica, resultaria a fixação ou a integração de nossa escola em sua comunidade local, com que travaria relações sistematizadas. Relações que ela estimularia, inicialmente, entre si e as famílias dos educandos, a quem iria oferecendo condições de ingerência em seus próprios destinos. Ingerência com que não só integraria as famílias com seu esforço, fazendo-as conscientes de suas limitações, a serem sanadas em conjunto, mas, também, com que ofereceria condições através de que as famílias experimentariam posições decisórias. Não será demais ressaltarmos a crença em experiências desse tipo, no mundo atual, como caminho de "enraização" do homem, em Mannheim como em Mareei, se bem que em termos diferentes. Experiências de afirmação do homem no seio de grupos limitados ou de pequenas comunidades. "Essas comunidades, diz Mareei, podem apresentar-se em formas diversas: uma paróquia, sem dúvida, porém igualmente uma simples empresa, uma 
escola, que sei eu"... E essa comunidade escolar não seria apenas a de professores e alunos, mas destes e mais todos os que nela trabalham e as famílias dos educandos e depois acrescida de outras tantas famílias de sua área de influência, que, motivadas, se incorporariam a seu trabalho. (Freire, 1962, p. 20)

\section{Considerações finais}

O período histórico que constitui o recorte da pesquisa encontra-se marcado pela transformação do Estado em agente promotor de uma nova configuração econômica, política e social no Brasil, sendo o eixo de sua ação o esforço de expansão do setor industrial. Neste contexto, o projeto de expansão e readequação da educação rural se encontrou conformado por um dado projeto político-social estruturado pelo objetivo de extensão dos hábitos, atitudes e formas de comportamento característicos de uma civilização industrial a ser implantada plenamente no Brasil, a qual teria no ambiente de trabalho fabril e no meio urbano a sua referência central.

Procurei mostrar que a iniciativa de promoção de um processo de desenvolvimento industrial, colocada em marcha pelo Estado nacional a partir da segunda metade do século passado, trouxe consigo um esforço de adequação da sociedade à necessidade de formação de um homem novo, isto é, da incorporação, por parte do conjunto da população nacional e, em particular, daqueles destinados a constituir a base humana da produção, de novos hábitos e maneiras de pensar mais condizentes com o processo de transformação da base econômica e da própria sociedade brasileiras no sentido da industrialização.

A escola primária, como espaço privilegiado de socialização, assumiria, neste contexto, um papel estratégico, na medida em que a ela caberia a tarefa de criação dos futuros construtores da nação: futuro cidadão-trabalhador capaz de orientar sua vivência comunitária e profissional em conformidade com os valores novos trazidos pelo movimento de expansão da civilização urbano-industrial. À escola rural, em particular, passaria a ser atribuído um papel estratégico como agente privilegiado do esforço de conformação da população do campo brasileiro frente aos valores, hábitos e práticas característicos, tanto do trabalho em moldes industriais, quanto do estilo de vida urbano que lhe é consentâneo.

$\mathrm{Na}$ formulação dos que pensavam as políticas educacionais do Estado brasileiro no momento histórico aqui discutido, as práticas pedagógicas presentes na escola primária rural seriam as promovedoras de uma aprendizagem daqueles mencionados valores, tanto por parte das crianças imediatamente sob seus cuidados, quanto por parte dos pais e da comunidade do entorno desta mesma escola.

Além disso, a escola primária rural deveria tornar-se um centro de irradiação dos novos valores do industrialismo. Seja na medida em que seu espaço físico se constitua como lugar de reunião da comunidade, com sua organização particular do tempo e do espaço, mas também apresentando a casa da professora como modelo de ordem e asseio, incorpora e reflete tais valores, seja na medida em que a professora por ela responsável deverá atuar também como organizadora de atividades e instituições coletivas capazes de educar, política e socialmente, os sujeitos sob influência direta ou indireta da escola primária rural. 
Em última instância, o que se buscava era a produção de um sujeito político particular capaz de assumir o papel de líder de sua comunidade e de exercer, no cumprimento deste papel, uma influência decisiva no sentido de modificar as práticas produtivas e as formas de pensar desta comunidade, bem como organizá-la a partir de modelos de participação e atuação política condizentes com aquela mencionada ordem social que então se desejava enraizar no país.

\section{Referências}

CAMPANHA NACIONAL DE EDUCAÇÃO RURAL. Revista da Campanha Nacional de Educação Rural. Brasília: MEC, v.6, n. 8, 1959.

FREIRE, Paulo. Escola primária para o Brasil. In: Revista Brasileira de Estudos Pedagógicos. Rio de Janeiro: Inep, v. 35, n. 82, 1962, p. 15-33.

GOULART, João Belchior. Mensagem presidencial de 1964. Brasília, Congresso Nacional, 1957.

HALL, Robert King. Observações e impressões sobre o ensino rural no Brasil. In: Revista Brasileira de Estudos Pedagógicos. Rio de Janeiro: Inep, v. 24, n. 38, 1950a, p. 110-125.

HALL, Robert King. Educação rural. In: Revista Brasileira de Estudos Pedagógicos. Rio de Janeiro: Inep, v. 24, n. 39, 1950b, p. 17-40.

KUBITSCHEK DE OLIVEIRA, Juscelino. Mensagem presidencial de 1956. Brasília: Congresso Nacional, 1956.

KUBITSCHEK DE OLIVEIRA, Juscelino. Mensagem presidencial de 1957. Brasília: Congresso Nacional, 1957.

MOREIRA, J. Roberto. Educação rural e educação de base. In: Revista Brasileira de Estudos Pedagógicos. Rio de Janeiro: Inep, v. 28, n. 67, 1957, p. 87-129.

NÓBREGA, Vandick Londres da (org.). Enciclopédia da legislação do ensino. Rio de Janeiro: DNE/MES, 1954, v. 2, p. 184-193.

RENAULT, Abgar. A professora rural e o cumprimento de sua missão. In: Revista Brasileira de Estudos Pedagógicos. Rio de Janeiro: Inep, v. 24, n. 60, 1955, p. 235-243.

FLÁVIO ANÍCIO ANDRADE é doutor em Educação pela Universidade de São Paulo. Professor adjunto no Departamento de Educação e Sociedade do Instituto Multidisciplinar da Universidade Federal Rural do Rio de Janeiro.

Endereço: Rua General Andrade Neves, 302/BI. 1-501 - 24001-210 - Niterói - RJ Brasil.

E-mail: flavioanicio@gmail.com.

Recebido em 5 maio de 2013.

Aceito em 9 de dezembro de 2013. 